\title{
La gobernabilidad en tiempos del COVID 19: una mirada desde Europa y Sudamérica
}

\section{Alejandro Di Giacomo'}

\section{Contribución en la Sección Panorama Social}

Resumen: Un virus de origen animal se ensañó con todo. Devoró vidas, hirió economías, desnudó las carencias de los sistemas sanitarios, evidenció la falta de respuestas y las contradicciones de muchos gobiernos y hasta planteó interrogantes sobre la libertad individual y el bien común. La pandemia por COVID-19 subrayó la importancia de criterios de gobernabilidad regional hoy debilitados, aunque necesarios para nivelar intereses nacionales herméticos, que derivan en desequilibrios e inequidades. Cuestionamiento que no sólo emergieron en la empobrecida y carente Sudamérica, sino también en la Unión Europea. El trabajo pretende un sobrevuelo por esos hechos recientes para, en medio de lo abrumador y lo trágico de la circunstancia, avivar nuevas reflexiones.

Hay más perplejidad y sombras que certezas en medio de la pandemia del coronavirus (SARS-CoV-2), aunque una de las pocas cosas claras es que el agente infeccioso tan feroz es capaz de igualar lo que antes de febrero de 2020 parecía inigualable. No hay geografía que no pueda penetrar, aunque drones, radares, muros de contención o ejércitos ultra profesionalizados vigilen. Tampoco hay Producto Interno Bruto capaz de resistir sus embates. EI PIB mundial caerá por lo menos 3\% este año, según la proyección del Fondo Monetario Internacional, un escenario peor que el de la crisis financiera 2008-2009 (FMI, 2020). Impulsado por las cercanías que impone un mundo global, híper interconectado, ataca con la misma voracidad a millones de kilómetros de distancia. Nace en Wuhan, salta a Bérgamo, pasa a Londres y llega hasta Ushuaia e islas Galápagos. Puntos muy distantes entre sí en el espacio absoluto, pero en el espacio relativo, medido a través del tiempo, la perspectiva es otra (Buzai, 2020).

La difusión del COVID-19 -nombre que la Organización Mundial de la Salud (OMS) dio a la enfermedad que produce este virus- demostró que todo proceso global actual, muy distinto a otras globalidades jalonadas en la historia de la humanidad (la conquista de América, el colonialismo, la era satelital), tiene una aceleración frenética que puede tornarse

\footnotetext{
${ }^{1}$ Licenciado en Periodismo de la Universidad Nacional de Lomas de Zamora (UNLZ). Se encuentra desarrollando su Tesis de Maestría en Ciencias Sociales en la Universidad de Palermo (UP). Es Coordinador de la carrera de Periodismo y Periodismo Deportivo de la UP. Periodista de profesión, actualmente Jefe de Redacción del servicio latinoamericano de la Agencia de noticias italiana (ANSA). Presidente de la Asociación de Corresponsales Extranjeros de Argentina (ACE). Correo electrónico: digipress62@gmail.com
} 
descontrolada. Y en ese empuje, la geografía aparece como una cuestión crucial y hasta la globalidad queda resignificada. Lo global penetrando lo local trastoca la organización social, la formación de identidades individuales y colectivas, la vida cotidiana misma. El "lugar" muta en algo "fantasmagórico" (Giddens, 1993, p. 30) y la pandemia ha llegado para mostrar todo lo tóxico del fenómeno.

El coronavirus tampoco diferencia estratificación social o poderío económico. De hecho, ingresó en el organismo de un habitante de la favela Rocinha de Río de Janeiro, y lo aniquiló (G1 Rio, 2020), pero también derrumbó a un empresario mexicano quien fue a esquiar a un exclusivo centro invernal de Colorado y murió por ese contagio (Hernández, 2020). Las estadísticas están mostrando que los adultos mayores son los más vulnerables, principalmente por el deterioro de su sistema inmunológico con el paso de los años y porque suelen tener otras enfermedades preexistentes. No obstante, han fallecido también niños y bebés, y en algunos países las franjas de contagio se sitúan entre los 35 y 45 años. Organismos jóvenes y sanos corren altos riesgos también probablemente a partir de la impronta genética, así lo advirtió la OMS (Pitt, 2020). Ninguna franja etaria se encuentra a salvo.

Este ente de proteínas y ácidos nucleicos fue capaz de igualar geopolíticas distantes, lejanas en kilómetros, historia y cultura; pero también en calidad de vida, en niveles de salud y educación, en presupuestos estatales, en aspiraciones ciudadanas y en posibilidades, como son los casos de Europa y Sudamérica.

Entre muerte y dolor, apareció nuevamente el estigma de una Unión Europea (UE) con dos velocidades. El norte opulento representado por Alemania, Países Bajos, Luxemburgo o Bélgica, frente a las naciones mediterráneas como Portugal, España, Italia y Grecia, relegadas y hostigadas por las hegemonías dominantes, que les objetan presupuestos desobedientes y ciertas rebeldías a la hora de comprimir el gasto público y pagar sus deudas. Bruselas, el centro del poder de la UE, busca siempre la restauración de la competitividad y exige la flexibilidad de la mano de obra, baja de costos salariales y de cargas fiscales. Pero el método de restricción de desequilibrios presupuestales supone una disminución del gasto público y, por lo tanto, un importante retiro del estado (en Guillén Romo, 1999). Un modelo de "producción de dinero a partir del dinero que resultó un fracaso" (Rapoport y Brenta, 2010, p.13).

Ese recorte sistemático fue letal en la pandemia, y se reflejó de forma atroz en el sistema hospitalario de Lombardía, con situaciones espeluznantes tales como las vividas por los médicos que debieron elegir a quién salvar y dejar morir (Canessa, 2020). También sucedió en el colapso de los hospitales de Madrid, con cinco pacientes para un respirador y camas instaladas en la cafetería (María, 2020). Asimismo, el supuestamente sólido NHS, el 
brioso sistema nacional de salud británico, que tuvo como estandarte a su personal médico y auxiliar, hizo milagros con la escasez de insumos y hasta se vio obligado a usar bolsas para residuos como protección en pleno Londres (Press, 2020) e, incluso, salvó la vida del primer ministro Boris Johnson. Por su parte la UCI del hospital St. Thomas vivió tres noches fatales (The Guardian, 09/04/2020).

Pero incluso dentro de una misma subregión, los efectos fueron distintos a partir de criterios de salud contrastantes, como en Gales e Inglaterra (Morgan, 2005). La UE se convirtió en una aventura inacabada en palabras de Bauman (2006), para quien el concepto de identidad europea conlleva la contemplación del otro, es decir de la otredad, concepto que, en esta crisis, se desvaneció. Las naciones que exigen los achiques del estado no contemplaron el debilitamiento de los servicios esenciales y el coronavirus lo mostró con descarnada impiedad.

El poderío económico y político de Merkel llevó a la canciller a prohibir el envío de máscaras de protección a Italia, cuando la península atravesaba su peor momento en la pandemia, con casi mil muertos diarios (Vita, 2020). También bajo el impulso de la líder germana, con fuerte respaldo de Países Bajos, la Unión Europea se mostró reacia a la intervención masiva y la asistencia financiera coordinada para impulsar el crecimiento tras el deterioro económico y social que acuñará la crisis (De Miguel, 2020). Finalmente, ambas cuestiones fueron zanjadas ante la magnitud de la hecatombe y la UE decidió un nuevo "Plan Marshall" de apoyo a sus socios más vulnerables (The Guardian, 24/04/2020).

También Sudamérica, un subcontinente no tan pobre pero muy desigual (Boyer, 2014), mostró en la crisis sanitaria sus dos caras: la de los países que priorizan el mercado, el control presupuestario y el aplanamiento del gasto público en fortalecimiento del crecimiento económico, con menos espacio al rol del estado (como Brasil, Chile y Colombia) y los que apuestan por un estado más presente y asistencial, privilegiando el crecimiento y el bienestar de la ciudadanía por encima del pago de las deudas, sin renunciar a los compromisos adquiridos pero aletargándolos (como el caso de Argentina).

Y justamente la crisis de la pandemia, con una enfermedad de veloz transmisión y largo alcance, encendió con más virulencia la inequidad, destruyó logros económicos que pasaron a tener un valor menor, tanto en escala estatal como individual, pasando a un segundo plano los programas de desarrollo sostenible. $\mathrm{Y}$ en uno u otro modelo, las poblaciones vulnerables quedaron así mayormente expuestas, más allá de la verticalidad del ataque del SARS-CoV-2 (Riggirozzi, 2020).

Sudamérica no tuvo ante la embestida del COVID-19, posiciones regionales uniformes, como tampoco las tuvo Europa. 
Argentina aplicó una cuarentena hermética y extensa, privilegiando la salud antes que la economía (La Nación, 12/04/20).

Brasil no logró coherencia ni en su propio territorio; lo cual se evidencia en las decisiones tomadas en los estados de San Pablo y Río de Janeiro que apostaron por encierros y restricciones, mientras el presidente Bolsonaro calificaba la pandemia de "gripecita", llamando a salir y trabajar (La Vanguardia, 25/03/2020) y hasta despidiendo funcionarios en medio de la crisis, resultando entonces que su país terminara siendo el más afectado de la región, al menos hasta finales de abril (ANSA Latina, 28/04/2020).

Ecuador tomo posiciones poco rígidas en los controles, conllevando una disparada de los casos positivos. Guayaquil colapsó, acumuló cadáveres y debió apelar a fosas comunes (Zibell, 2020).

Chile aplicó cuarentenas en unas comarcas y en otras no y los recortes del presidente Piñera reavivaron la protesta social, incluso en medio de las restricciones (ANSA Latina, 27/04/2020). Son sólo algunos ejemplos de la falta de uniformidad de criterios ante un enemigo común, como lo llaman todos los gobiernos. Claramente, se trata de políticas de puertas adentro que acunan un renacimiento nacionalista, típico cuando se ven amenazas a la seguridad y el Estado se aboca a proteger a sus ciudadanos (Riggirozzi, 2020).

La misma autora describe muchos pilares de gobernanza regional, construidos en los últimos años, pero que han quedado deshilachados y arrumbados. Los bloques de Mercosur y Unasur supieron, tiempo atrás, aunar esfuerzos en pos de iniciativas directamente orientadas a la cartera de salud de cada uno de los países miembros. Hoy Mercosur tiene otros ejes, más económicos que políticos, al tiempo que la mayor parte de los miembros de la Unasur ya han abandonado el grupo por diferencias ideológicas. Sudamérica sufre el peso de su deuda externa, principalmente con el FMI, y en los últimos años: "los datos muestran una disminución del peso del sector gubernamental y el aumento del correspondiente al sector financiero y su fuerte presencia como emisor de valores internacionales" en todo el mundo (Radio Mercosur, 2020).

Una tormenta perfecta para debilitar los sistemas de salud al punto de volverlos frágiles, casi inoperantes frente a una pandemia.

\section{Conclusión}

Una de las tantas lecciones de la pandemia de este coronavirus de origen animal nacido en Wuhan, es la necesidad de políticas regionales que permitan afrontar problemáticas que en un mundo globalizado rápidamente tienen un efecto de contagio o de impacto que sobrepasa el lugar de génesis. 
Contar con una gobernanza regional, con criterios de la geografía de la salud, con discusiones para llegar a acuerdos comunes, son pilares insoslayables en un mundo híper conectado. La falta de unión, de estándares acordados y de políticas sanitarias entrelazadas, debilitan aún más lo endeble de la situación, y sabemos que un corpus enfermo es presa fácil de cualquier tempestad, sea COVID-19, dengue, sarampión o desnutrición.

\section{Referencias}

ANSA Latina (27 de abril de 2020). 33 detenidos por desórdenes en Plaza Italia. http://www.ansalatina.com/americalatina/noticia/sociedad/2020/04/28/33detenidos-or-desordenes-en-plaza-italia_5fca338d-d996-48ce-9966$2 a 4 e 4 b 2 b 1 f 8 e . h t m l$

ANSA Latina (28 de abril de 2020). América Latina, 180 mil casos y 9 mil muertes. http://www.ansalatina.com/americalatina/noticia/sociedad/2020/04/28/americalatina-180-mil-casos-y-9-mil-muertes_89076116-9a9c-473a-8b0831954da0e8d3.html

Bauman, Z. (2006). Europa: una aventura inacabada. Madrid: Losada

Boyer, R. (2014). Los mundos de la desigualdad. Un análisis a partir de la teoría de la regulación y una respuesta a Thomas Piketty. Buenos Aires: Editorial Octubre.

Buzai, G (2020). De Wuhan a Luján. Evolución espacial del COVID-19. Posición -Instituto de Investigaciones Geográficas Universidad Nacional de Luján. https://www.researchgate.net/publication/340716256_De_Wuhan_a_Lujan_Evolu cion_espacial_del_COVID-19

Canessa, F. (26 de marzo de 2020). Coronavirus, rivelazioni choc dai medici del Villa Scassi: "Costretti a lasciarli morire, è una mattanza". Genova24.it. https://www.genova24.it/2020/03/coronavirus-rivelazioni-choc-dai-medici-delvilla-scassi-costretti-a-lasciarli-morire-e-una-mattanza-233172/

De Miguel, B. (24 de abril de 2020). Dos mujeres al rescate del sur. El País, diario. https://elpais.com/economia/2020-04-24/dos-mujeres-al-rescate-del-sur.html

Fondo Monetario Internacional (FMI) (abril 2020). Perspectivas de la Economía Mundial, abril de 2020. https://www.imf.org/es/Publications/WEO/Issues/2020/04/14/weoapril-2020

G1 Rio (23 de abril de 2020). Associaçao de Moradoresa Rocinha pede que pessoas fiquem em casa após morte de morador com sintomas de Covid-19. 
https://g1.globo.com/rj/rio-de-janeiro/noticia/2020/04/23/associacao-demoradores-da-rocinha-pede-que-pessoas-fiquem-em-casa-apos-morte-demorador-com-sintomas-de-covid-19.ghtml

Giddens, A. (1993). Las consecuencias de la modernidad. Madrid: Alianza.

Guillen Romo, H. (2011). Integración monetaria, crisis y austeridad en Europa. Revista Problemas del Desarrollo, 45(165), 113-140. Recuperado de http://www.scielo.org.mx/scielo.php?script=sci_arttext\&pid=S030170362011000200006

Hernández, A. (13 de abril de 2020). Muere Jaime Ruíz Sacristán, presidente de la Bolsa de Valores. El Universal, diario. https://www.eluniversal.com.mx/cartera/muerejaime-ruiz-sacristan-presidente-de-la-bolsa-de-valores

La Nación, diario (12 de abril de 2020). Alberto Fernández, sobre las medidas por el coronavirus: "El dilema entre economía y salud es falso". https://www.lanacion.com.ar/politica/alberto-fernandez-medidas-coronavirus-eldilema-economia-nid2353339

La Vanguardia, diario (25 de marzo de 2020). Bolsonaro vuelve a calificar el coronavirus de "gripecita" y critica el confinamiento.

https://www.lavanguardia.com/internacional/20200325/4889399693/bolsonarocalifica-coronavirus-gripecita-critica-confinamiento-brasil.html

Maria, P. (03 de abril de 2020). El colapso de las UCI endurece el triaje: "Hay cinco enfermos para un solo tubo". La información, diario https://www.lainformacion.com/asuntos-sociales/coronavirus-ucis-seleccionpacientes-triaje-hospitales/6556311/

Morgan, K. (2005). Ciudades-región en Europa: innovación, aprendizaje y nueva gobernanza territorial. Repositori Universitat Jaume I. Recuperado de http://repositori.uji.es/xmlui/handle/10234/128872

Pitt, L. (21 de abril de 2020). Coronavirus: las teorías de por qué la COVID-19 puede llegar a causar la muerte de pacientes jóvenes y aparentemente sanos. BBC News Mundo. https://www.bbc.com/mundo/noticias-52326745

Press, C. (6 de abril de 2020). "Nos tenemos que poner bolsas de basura en la cabeza": el testimonio de una médica que atiende a los pacientes más graves de COVID-19 en Reino Unido. BBC News. https://www.bbc.com/mundo/noticias-52173310

Radio Mercosur (30 de abril de 2020). Prestar atención al endeudamiento. http://radiomercosur.com/contenidos/2018/05/10/Editorial_4403.php 
Rapoport, M. y Brenta, N. (2010). Las grandes crisis del capitalismo contemporáneo. Buenos Aires: Capital Intelectual.

Riggirozzi, P. (2020). Coronavirus y el desafío para la gobernanza regional en América Latina. Análisis Carolina. Fundación Carolina. Recuperado de https://www.fundacioncarolina.es/wp-content/uploads/2020/03/AC-12.2020.pdf

The Guardian, diario (9 de abril de 2020). Boris Johnson moved from intensive care but stays in hospital. https://www.theguardian.com/global/2020/apr/09/boris-johnsonmoved-from-intensive-care-but-stays-in-hospital

The Guardian, diario (24 de abril de 2020). The Guardian view on the EU and Covid-19: better late than never. Editorial. https://www.theguardian.com/commentisfree/2020/apr/24/the-guardian-view-onthe-eu-and-covid-19-better-late-than-never

Vita, L. (13 de marzo de 2020). Stop all'export di mascherine: la Germania "soffoca" I'Italia. il Giornale.it. https://www.ilgiornale.it/news/mondo/stop-allexport-mascherinegermania-soffoca-litalia-1840258.html

Zibell, M. (26 de abril de 2020). Coronavirus en Ecuador: la tragedia de las familias de Guayaquil que no encuentran a sus muertos. BBC News https://www.bbc.com/mundo/noticias-america-latina-52407158 